\title{
Microstrip antenna with DGS based on CSRR array for WiMAX applications
}

\author{
Ajay V.G., Parvathy A.R.,Thomaskutty Mathew \\ School of Technology and Applied Sciences, India
}

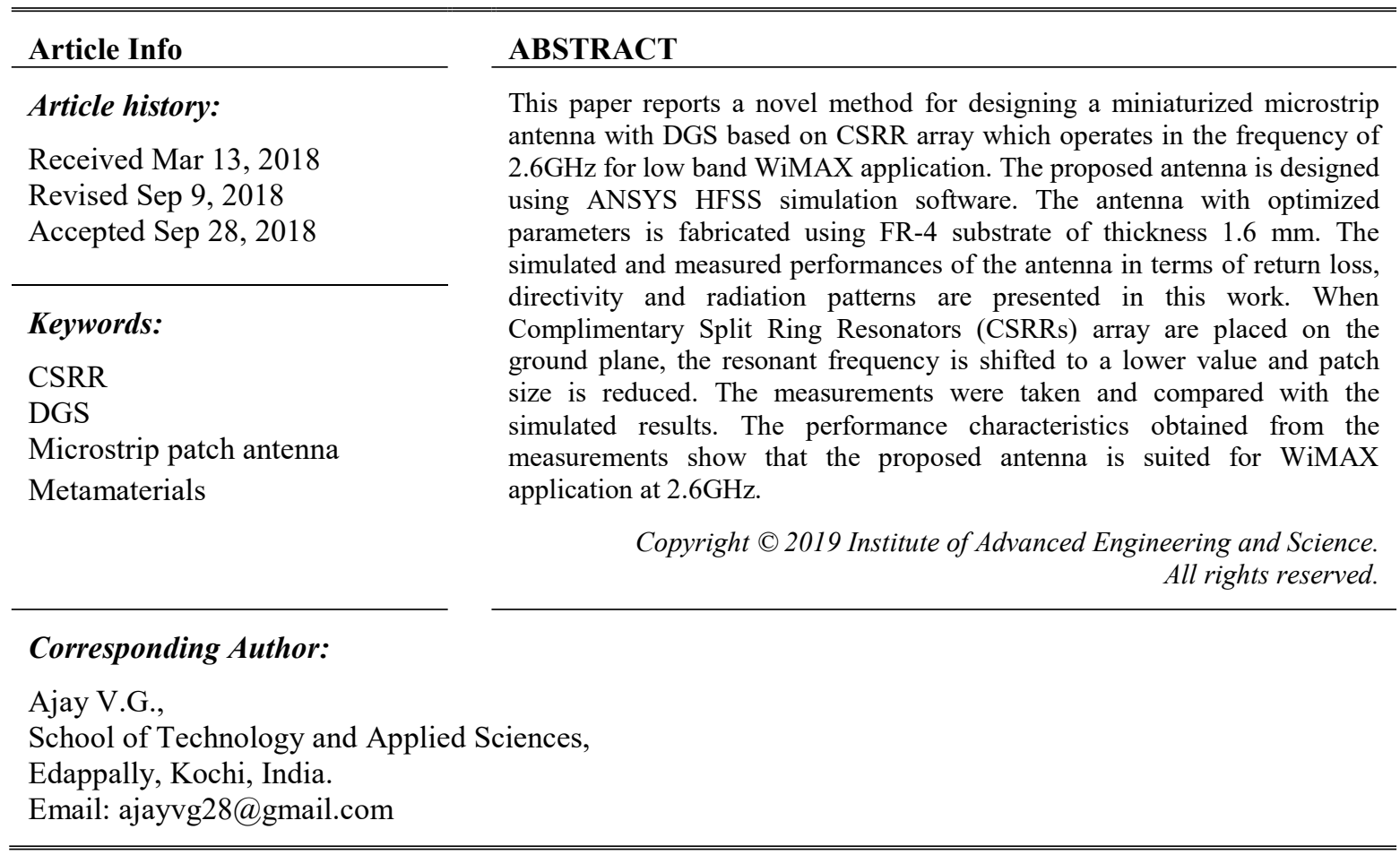

\section{INTRODUCTION}

Metamaterials are artificially structured materials that show cumulatively negative values of magnetic permeability and electric permittivity upon a distinct frequency band [1], [2]. The use of the metamaterials in microstrip antenna design improve some of the basic features of antennas like gain, impedance matching, efficiency,bandwidth etc. [3].The concept of metamaterial was conceived around 1967 by Russian physicist Victor Veselago. The first metamaterial structure[4] was fabricated by Smith D.R etal in the year 2000.Several structures were proposed by the scientists to form metamaterials. The commonly used structures are the Split Ring Resonators (SRRs) and Complementary Split Ring Resonators (CSRRs).

The metamaterial structure can be designed in many ways and the introduction of Defected Ground Structure (DGS) on ground plane will effectively increase the inductance and capacitance of the overall electric circuits [5], [6].The drawbacks associated with the miniaturization of antennas are narrow band width expensive and reduction in radiation efficiency [7].Some of the design methods to overcome these drawbacks are Corrugation Structure [8], shorting pin [9] and Iris Structure [10]. The limitations of these miniaturization methods are poor performance and complexity of structures. The metamaterial based single CSRR structured antenna was designed at resonant frequency of $3.5 \mathrm{GHz}[11]$. The reduction in size of the patch antenna was accomplished by loading CSRR on patch antenna [12]. Preliminary studies were done based on the miniaturization of antennas with defected ground structure [13-17].

In this paper we present the design and development of a $2.6 \mathrm{GHz}$ miniaturized microstrip antenna with DGS based on CSRR array for WiMAX applications. The resonant frequency is reduced by placing CSRR array on the ground plane with same physical size as compared to single layer CSRR structure. The miniaturization of antenna has been achieved by using DGS based on CSRR array structure with 
microstrip patch antenna.The design performance of patch antennas are affected by many split ring parameters.Some of the parameters are shape of the SRRs, width of the rings, and gap between rings.

\section{ANTENA DESIGN SPECIFICATIONS}

The proposed microstrip antenna with DGS based on CSRR array was designed at $2.6 \mathrm{GHz}$ for WiMAX application. The antennas were designed using FR-4 substrate of thickness $1.6 \mathrm{~mm}$ and $\varepsilon \mathrm{r}=4.4$. The physical size of the proposed antenna is same as compared with single CSRR structured microstrip antenna having $3.5 \mathrm{GHz}$ resonant frequency. By adding CSRR array structure on the ground plane,the resonant frequency of single CSRR structured antenna with $3.6 \mathrm{GHz}$ is reduced to $2.6 \mathrm{GHz}$. The desired value of resonant frequency for the antenna can be tuned by adjusting the various geometric parameters and size of the CSRR. Two design methods were compared in this study, one for the single SRR antenna and the other for microstrip antenna with DGS based on CSRR array. The dimensions of both single and microstrip antenna with DGS based on CSRR array are tabulated in Table 1.

Table 1. Parameters of Single CSRR and CSRR Array Structured Microstrip Patch Antennas

\begin{tabular}{cc}
\hline Parameters & Dimensions $(\mathrm{mm})$ \\
\hline Ls & 31.04 \\
Ws & 37.76 \\
Lp & 16.475 \\
Wp & 20 \\
Wf & 3.059 \\
Wg & 6.11 \\
y0 & 4.61 \\
Lf & 12.161 \\
Ls & 31.04 \\
Ws & 37.76 \\
Lp & 16.475 \\
\hline
\end{tabular}

Figure 1 represents the geometry of the proposed CSRR array structured microstrip antenna. The two circular rings has inner radius $r_{1}=4 \mathrm{~mm}, r_{3}=5 \mathrm{~mm}$ and outer radius $r_{2}=4.5 \mathrm{~mm} \& \mathrm{r}_{4}=5.5 \mathrm{~mm}$ respectively. The gap ( $\mathrm{g}$ ) of the ring is $2.24 \mathrm{~mm}$ and width is $0.5 \mathrm{~mm}$. The distance between circular rings $\left(\mathrm{d}_{1} \& \mathrm{~d}_{2}\right)$ along $\mathrm{X}$ direction and $\mathrm{Y}$ directions are $12 \mathrm{~mm}$ and $14 \mathrm{~mm}$ respectively.

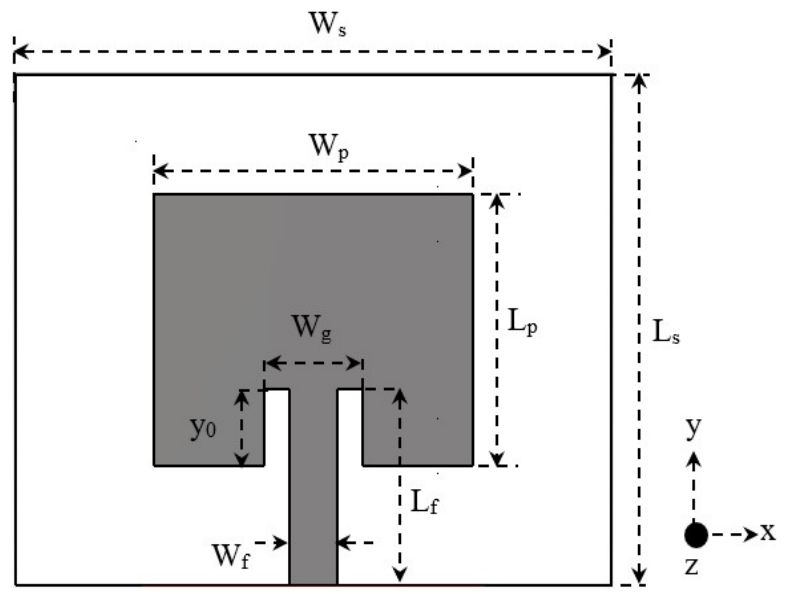

(a) Top view

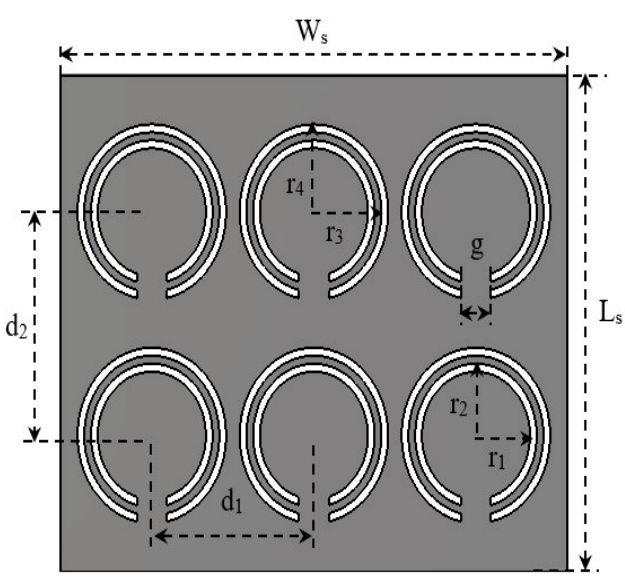

(b) Bottom view

Figure 1. CSRR Array structured microstrip antenna

Figure 2 shows the physical view of the microstrip antenna with DGS based on CSRR array and fabrication was done using the FR-4 substrate. The resonant frequency of the microstrip antenna with DGS based on CSRR array was shifted to $2.6 \mathrm{GHz}$. 


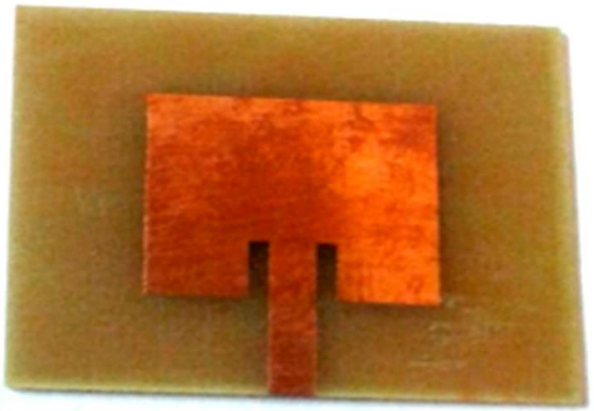

(a) Top view

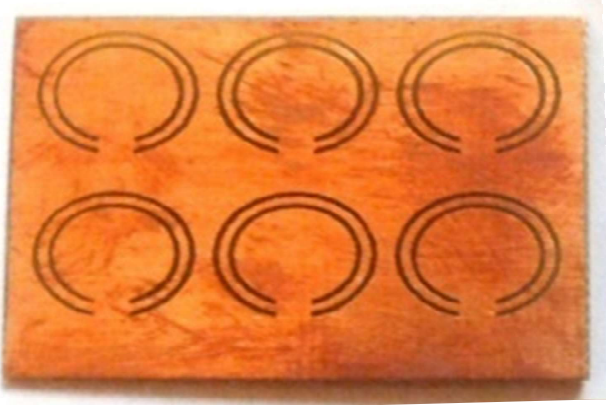

(b) Bottom view

Figure 2. Physical view of fabricated antenna

\section{RESULTS AND ANALYSIS}

\subsection{Return Loss}

Figure 3 depicts the simulated return loss characteristics of single CSRR antenna and the proposed miniaturized microstrip antenna with DGS based on CSRR array. The antenna shows good performance in the respective frequency band. The simulation results for return loss single CSRR microstrip antenna is $-15.6 \mathrm{~dB}$ and that of microstrip antenna with DGS based on CSRR array is $-13.8 \mathrm{~dB}$. Bandwidth of the antenna can be found from the return loss plot. Figure 4 shows the simulated and measurement results of return loss S11 from microstrip antenna with DGS based on CSRR array.

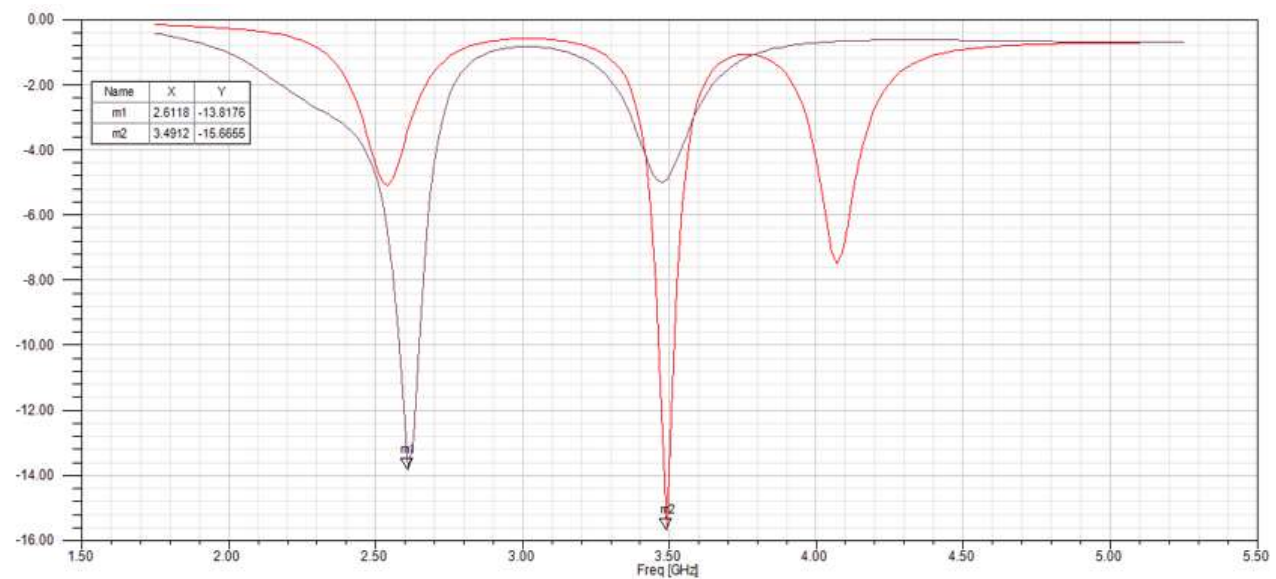

Figure 3. Simulated results of single \&CSRR array structured antenna

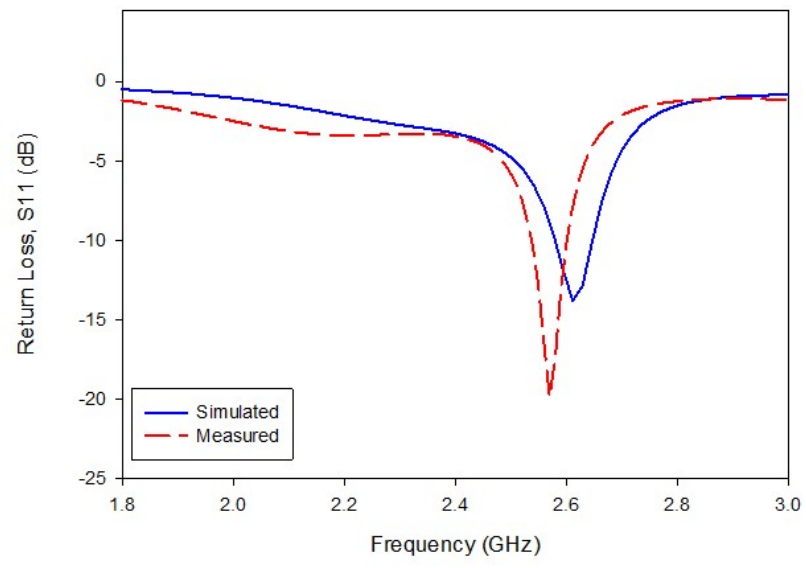

Figure 4. Simulated and measured variation of return loss characteristics 


\subsection{Directivity}

The simulated results of directivity for single CSRR structured antenna is 5.84 and the microstrip antenna with DGS based on CSRR array is 4.57 . The values of directivity infer that the antennas are highly directive. Directivity of the antennas are shown in Figure 5 and Figure 6.
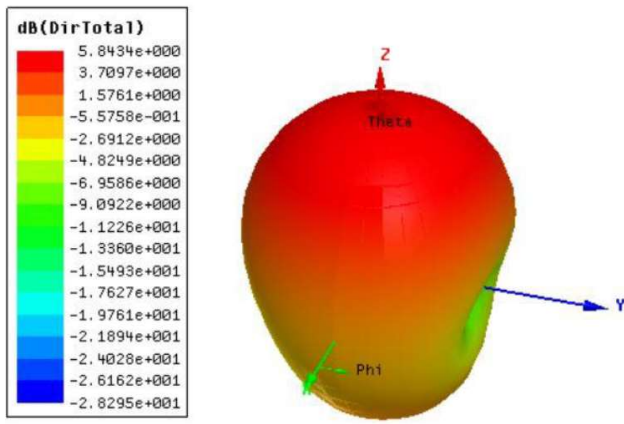

Figure 5. Directivity of single CSRR structure based microstrip antenna
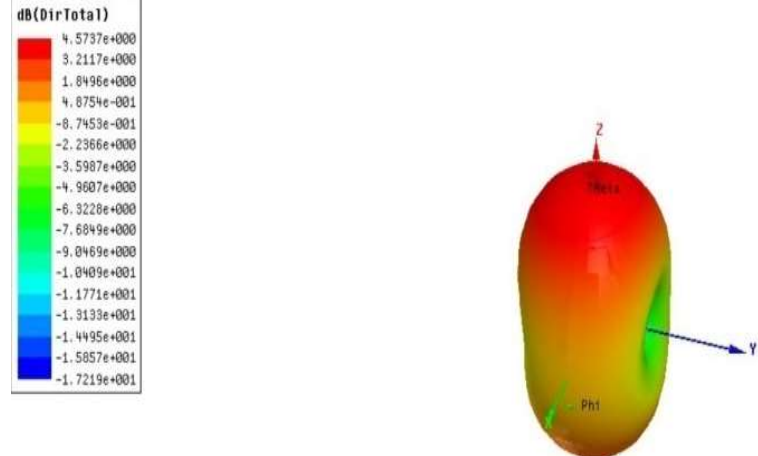

Figure 6. Directivity of microstrip antenna with DGS based on CSRR array

\subsection{Radiation Pattern}

Figure 7 represents the measured results for radiation pattern of the proposed microstrip antenna with DGS based on CSRR array.

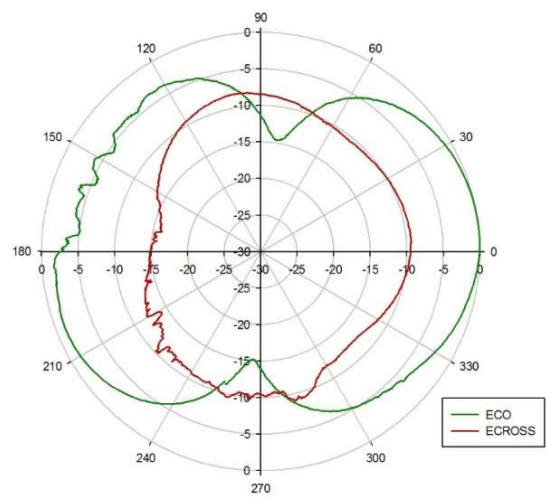

(a) E plane pattern

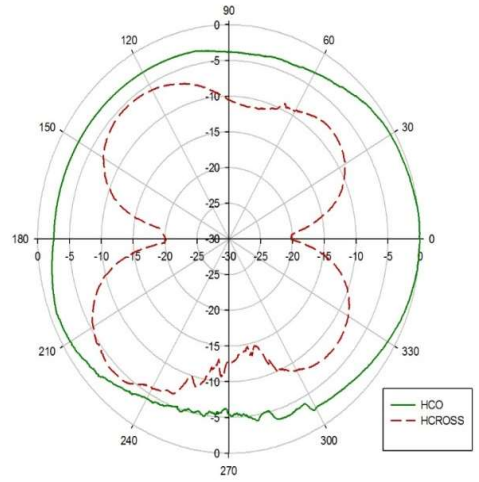

(b) H plane pattern

Figure 7. Measured Radiation pattern of the proposed CSRR array structured antenna

A comparison between the proposed work and a recently published antenna structure with the same physical size is tabulated in Table 2. As per the comparison, the proposed miniaturized microstrip antenna with DGS based on CSRR array is compact along with reduction in resonant frequency.

Table 2. Comparison Chart of the Proposed Antenna and Recently Published Paper

\begin{tabular}{ccc}
\hline Paper & Frequency Return loss & Size \\
\hline Ajay [11] & $3.5 \mathrm{GHz}-15.8 \mathrm{~dB}$ & $31.04 \times 37.76 \mathrm{~mm}^{2}$ \\
$\begin{array}{c}\text { Proposed Microstrip Antenna with } \\
\text { DGS based on CSRR array for } \\
\text { WiMAX Applications }\end{array}$ & $2.6 \mathrm{GHz}-13.8 \mathrm{~dB}$ & $31.04 \times 37.76 \mathrm{~mm}^{2}$ \\
\hline
\end{tabular}




\section{CONCLUSION}

The miniaturized microstrip antenna with DGS based on CSRR array was designed using ANSYS HFSS and analyzed the various performance characteristics. The resonant frequency of the microstrip antenna with DGS based on CSRR array has been reduced from $3.5 \mathrm{GHz}$ to $2.6 \mathrm{GHz}$ with the same physical size. The performance analysis of the microstrip antenna with DGS based on CSRR array was verified from measured and simulated results. The simulated results of directivity at $2.6 \mathrm{GHz}$ is 4.57 and the return loss is 13.80 .

\section{REFERENCES}

[1] D. R. Smith, W. J. Padilla, D. C. Vier, S. C. Nemat-Nasser, and S. Schultz, "Composite Medium with Simultaneously Negative Permeability and Permittivity”, Phys. Rev. Lett., vol. 84, no. 18, pp. 41844187, 2000

[2] J.B. Pendry, A.J. Holden, D. J. Robbins, and W. J. Stewart, "Magnetism from Conductors and Enhanced Nonlinear Phenomena”, IEEE Trans.Microw. Theory Tech., vol. 47, no. 11, pp. 2075-2084, November 1999.

[3] J.S Lim, C.B. Kim, J.S. Jang et al., "Design of a subwavelength patch antenna using metamaterials",in Proc. Microwave Conference, EuMC 2008, 38th European, pp. 547-550, Amsterdam, 2008.

[4] V.G. Veselago, "The Electrodynamics of Substances With Simultaneously Negative Values of and", Sov. Phys. Uspekhi, vol. 10, no.4, pp.509-514, January-February,1968.

[5] P. Lokhande, B. Salokhe, "Design \& Simulation of Circular Microstrip Antenna with Defected Ground Structure (DGS) for WLANApplications," IOSR Journalof Electronics and Communication Engineering (IOSR-JECE), pp. 46-50, 2013.

[6] Samreen, C.Roshni, K. Shailesh, "Miniaturized Hexagonal-Shaped Fractal SLot Microstrip Antenna for WLAN Application using DGS", in Proc. Conference on Advances in Communication and Control Systems(CAC2S), pp. 388-392, 2013.

[7] H.A.Jang, D.O. Kim, C.Y. Kim, "Size Reduction of Patch Antennas using CSRRs Ground plane", in Proc. Progress In Electromagnetics Research Symposium Proceedings, KL, Malaysia, March 27-30, 2012.

[8] Lee, S. J. Woo, M.Ryu, H.Shin, "Corrugated Circular Microstrip Patch Antennas for Miniaturization" Electronic Letters ,vol. 38, no.6, pp. 262-263, 2003.

[9] R.Waterhouse, "Small Microstrip Antennas", Electronic Letters, vol.31,pp. 604-605,1995.

[10] J .Seo, J. Woo, "Miniaturization of Microstrip Antennas Using Iries", Electronic Letters, vol.33, pp. 718-719,2004.

[11] V.G. Ajay, Thomaskutty Mathew, "Size reduction of Microstrip patch antenna through metamaterial approach for WiMMAX Application", in Proc. IEEE International Conference On Wireless Communications, Signal Processing And Networking (WiSPNET), pp. 379-381, March 2017.

[12] S.Mohammad Sharawi, U.Muhammad Khan, B. Ahmad Numan, N. Daniel Aloi, "A CSRR Loaded MIMO Antenna System for ISM Band Operation," IEEE Transactions on antennas and propagation, vol. 61, no. 8, pp. 4265 - 4274, 2013.

[13] I. P. Sari, A. Munir, "Defected ground structure for bandwidth improvement of artificial magnetic conductor-based microwave absorber", in Proc. International Conference on Telecommunication Systems,Services, and Applications (TSSA), vol. 1, no. 3, pp. 200-203, October 2012.

[14] N. Ripin, W.Saidy, A.A. Sulaiman, N. E.A. Rasheed, M. F. Hussin, "Miniaturization of microstrip patch antenna through metamaterial approach" in Proc. IEEE Student Conference on Research and Development, 16-17 December 2013.

[15] N. Nada Tawfeeq, "Size Reduction and Gain Enhancement of a Microstrip Antenna using Partially Defected Ground Structure and Circular/Cross Slots", International Journal of Electrical and Computer Engineering (IJECE), vol. 7, no.2, April 2017.

[16] P.K. Singhal, Bimal Garg, "Design and Characterization of Compact Microstrip Patch Antenna Using "Split Ring" Shaped Metamaterial Structure", International Journal of Electrical and Computer Engineering (IJECE), vol. 2, no. 5, October 2012.

[17] S. Elajoumi, A. Tajmouati, A Errkik, Am.Sanchez, M. Latrach, "Microstrip Rectangular Monopole Antennas with Defected Ground for UWB Applications", International Journal of Electrical and Computer Engineering (IJECE), vol. 7, no. 4, August 2017. 


\section{BIOGRAPHIES OF AUTHORS}
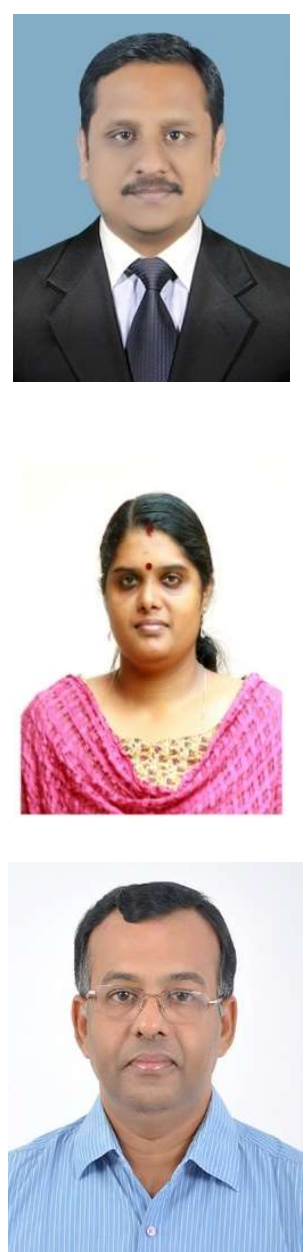

Ajay V.G. was born in Kerala, India on $25^{\text {th }}$ March 1979.He recieved his Bachelor's Degree in Electronics \& Communication Engineering from Mahatma Gandhi University, Kerala, in 2002 and Master's Degree in Applied Electronics from Mahatma Gandhi University, Kerala, in 2009. From 2003 to 2013 he worked as Leturer, Asst. Professor andAssociate Professor in ECE Dept.at Caarmel Engineering College, Perunad-Ranny. From 2013to 2016 he worked as Associate Professor in ECE Dept. at LBSITW, Trivandrum. He is currently pursuing his Ph.D Degree in Microwave Electronics at School of Technology \& Applied Sciences, Mahatma Gandhi Univerisity Regional Center, Edappally, Kochi. His current areas of research include Microstrip Patch Antennas, Metamaterials, RFID etc.

E-mail: ajayvg28@gmail.com

Parvathy A. R. was born in Kerala, India on $9^{\text {th }}$ July 1987. She recieved her Bachelor's Degree in Electronics \& Communication from University of Kerala, in 2009 and Master's Degree in Communication Engineering from Mahatma Gandhi University, Kerala, in 2012. She is currently pursuing her Ph.D Degree in Microwave Electronics at School of Technology \& Applied Sciences, Mahatma Gandhi Univerisity Regional Center, Edappally, Kochi with UGC Junior Research Fellowship. Her current areas of research include Microstrip Printed Slot Antennas, RFID etc.

E-mail: arpinmvk@gmail.com

Thomaskutty Mathew was born in Kerala, India on $30^{\text {th }}$ May 1967. He received his Ph.D Degree in Microwave Electronics from Cochin University of Science and Technology Cochin, India in 1997. From 1995 to 1999 he worked as a Lecturer in Physics at Christ College, Irinjalakuda, India. Since 1999, he is working as faculty of the Department of Electronics, School of Technology \&Applied Sciences, Mahatma Gandhi University Regional Center, Edappally, Kochi, India and presently working as Reader in the Department. During the period 2006-2008, he worked as a Post Doctoral Research Associate at Department of Electronics, University of Kent, Canterbury, U.K. His current area of research activites are in Microstrip antennas, Radar Cross Section, RFID, Wireless Sensor Networks etc. He is a member of IEEE Antennas and propagation society and IET (U.K).

E-mail: drtkmathew@gmail.com 